\title{
Article \\ Exceedingly High Performance Top-Gate P-Type SnO Thin Film Transistor with a Nanometer Scale Channel Layer
}

\author{
Te Jui Yen ${ }^{1}$, Albert Chin ${ }^{1, *(1)}$ and Vladimir Gritsenko ${ }^{2,3,4}$ \\ 1 Department of Electronics Engineering, National Chiao Tung University, Hsinchu 300, Taiwan; \\ yenrick42269.ee05g@g2.nctu.edu.tw \\ 2 Rzhanov Institute of Semiconductor Physics, Siberian Branch, Russian Academy of Sciences, \\ Novosibirsk 630090, Russia; grits@isp.nsc.ru \\ 3 Novosibirsk State University, 2 Pirogov Street, Novosobirsk 630090, Russia \\ 4 Novosibirsk State Technical University, 20 Marks Avenue, Novosibirsk 630073, Russia \\ * Correspondence: achin@nctu.edu.tw; Tel.: +886-3-5731-841
}

Citation: Yen, T.J.; Chin, A.;

Gritsenko, V. Exceedingly High

Performance Top-Gate P-Type SnO

Thin Film Transistor with a

Nanometer Scale Channel Layer.

Nanomaterials 2021, 11, 92.

https://doi.org/10.3390/nano11010092

Received: 16 December 2020

Accepted: 30 December 2020

Published: 3 January 2021

Publisher's Note: MDPI stays neutral with regard to jurisdictional clai$\mathrm{ms}$ in published maps and institutional affiliations.

Copyright: $\odot 2021$ by the authors. Licensee MDPI, Basel, Switzerland. This article is an open access article distributed under the terms and conditions of the Creative Commons Attribution (CC BY) license (https:// creativecommons.org/licenses/by/ $4.0 /)$.

\begin{abstract}
Implementing high-performance n- and p-type thin-film transistors (TFTs) for monolithic three-dimensional (3D) integrated circuit (IC) and low-DC-power display is crucial. To achieve these goals, a top-gate transistor is preferred to a conventional bottom-gate structure. However, achieving high-performance top-gate p-TFT with good hole field-effect mobility $\left(\mu_{F E}\right)$ and large oncurrent/off-current $\left(\mathrm{I}_{\mathrm{ON}} / \mathrm{I}_{\mathrm{OFF}}\right)$ is challenging. In this report, coplanar top-gate nanosheet $\mathrm{SnO}$-TFT with high $\mu_{F E}$ of $4.4 \mathrm{~cm}^{2} / \mathrm{Vs}$, large $\mathrm{I}_{\mathrm{ON}} / \mathrm{I}_{\mathrm{OFF}}$ of $1.2 \times 10^{5}$, and sharp transistor's turn-on subthreshold slopes (SS) of $526 \mathrm{mV} /$ decade were achieved simultaneously. Secondary ion mass spectrometry analysis revealed that the excellent device integrity was strongly related to process temperature, because the $\mathrm{HfO}_{2} / \mathrm{SnO}$ interface and related $\mu_{F E}$ were degraded by $\mathrm{Sn}$ and $\mathrm{Hf}$ inter-diffusion at an elevated temperature due to weak $\mathrm{Sn}-\mathrm{O}$ bond enthalpy. Oxygen content during process is also crucial because the hole-conductive p-type $\mathrm{SnO}$ channel is oxidized into oxygen-rich n-type $\mathrm{SnO}_{2}$ to demote the device performance. The hole $\mu_{F E}, \mathrm{I}_{\mathrm{ON}} / \mathrm{I}_{\mathrm{OFF}}$, and $S S$ values obtained in this study are the best-reported data to date for top-gate p-TFT device, thus facilitating the development of monolithic 3D ICs on the backend dielectric of IC chips.
\end{abstract}

Keywords: monolithic 3D; 3D brain-mimicking IC; SnO TFT

\section{Introduction}

Metal-oxide Thin film transistors (TFTs) [1-35] have drawn considerable attention due to their high mobility, low fabrication temperature, and simple fabrication process, making them suitable for advanced display [1-6] and monolithic three-dimensional (3D) integrated circuit (IC) [15-21] on amorphous inter-metal-dielectric (IMD) of a Si chip. To reach low DC power consumption, both high performance $\mathrm{n}$ - and p-type TFTs are necessary to form the complementary metal-oxide-semiconductor (CMOS) logic. Although high-performance $\mathrm{n}$-TFTs with high field-effect mobility $\left(\mu_{F E}\right)$, sharp subthreshold swing (SS), and large on-current/off-current $\left(\mathrm{I}_{\mathrm{ON}} / \mathrm{I}_{\mathrm{OFF}}\right)$ values [12-15] have been reported, achieving reasonable performance p-TFTs is much more challenging $[16,17,36,37]$. Moreover, a top-gate structure is more suitable than a conventional bottom-gate device for high integration density and easy fabrication [24-26]. Previously, we have reported the bottom-gate SnO p-TFT, which has higher $\mu_{F E}$ than $\mathrm{Cu}_{2} \mathrm{O}$ p-TFT $[16,17]$. In the current study, we further used the $\mathrm{SnO}$ channel to fabricate top-gate coplanar nanosheet p-TFT. Because the gate insulator was deposited after the SnO layer, the deposition and post-annealing conditions are crucial to device performance. This is because the p-type $\mathrm{SnO}$ is highly sensitive to oxygen partial pressure $\left(O_{p p}\right)$ and annealing temperature, and can be easily oxidized into oxygen-rich $\mathrm{Sn}_{2} \mathrm{O}_{3}, \mathrm{Sn}_{3} \mathrm{O}_{4}$, or $\mathrm{SnO}_{2}$ [27-29]. Moreover, the weak $\mathrm{Sn}-\mathrm{O}$ bond enthalpy [38] facilitates Sn diffusion into high-dielectric-constant (high- $\mathrm{K}$ ) $\mathrm{HfO}_{2}$ insulator at elevated temperature, 
thus degrading device performance. In this study, the above challenges were successfully overcome, and high-performance top-gate nanosheet $\mathrm{SnO}$ p-TFT was achieved with high $\mu_{F E}$ of $4.4 \mathrm{~cm}^{2} / \mathrm{Vs}$, large $\mathrm{I}_{\mathrm{ON}} / \mathrm{I}_{\mathrm{OFF}}$ of $1.2 \times 10^{5}$, and sharp $S S$ of $526 \mathrm{mV} /$ decade, indicating a high potential for future monolithic $3 \mathrm{D}$ and brain-mimicking IC applications [15,17-21].

\section{Materials and Methods}

The coplanar top-gate nanosheet $\mathrm{SnO}$ p-TFTs were fabricated on the $\mathrm{Si}$ wafer with a 500-nm-thick $\mathrm{SiO}_{2} \mathrm{IMD}$ layer on $\mathrm{Si}$ wafer. The 7-nm-thick nanosheet $\mathrm{SnO}$ layer was deposited through reactive sputtering with $50 \mathrm{~W}$ DC power from a Sn target under $O_{p p}$ values of $14.2 \%, 25 \%$, and $33.3 \%$ ambient, respectively. All the SnO p-TFT samples were annealed under $200{ }^{\circ} \mathrm{C}$ in $\mathrm{N}_{2}$ ambient for $45 \mathrm{~min}$. Next, 40 -nm high work-function $\mathrm{Ni}$ was deposited using an e-gun evaporator for the Schottky-barrier source and drain electrodes [39,40]. Subsequently, 50-nm $\mathrm{HfO}_{2}$ gate dielectric was deposited by e-beam evaporation with a rate of $0.2 \AA /$ sec. $\mathrm{HfO}_{2}$ post-annealing was performed in $\mathrm{N}_{2}$ ambient at $100{ }^{\circ} \mathrm{C}$ and $200{ }^{\circ} \mathrm{C}$. Finally, 50-nm gate electrode $\mathrm{Al}$ was deposited and patterned. The transistor's length and width were 50 and $400 \mu \mathrm{m}$, respectively. The current-voltage characteristics of top-gate SnO p-TFT were measured through the HP4155B parameter analyzer and a probe station. The field-effect mobility values $\left(\mu_{F E}\right)$, subthreshold slope $(S S)$ and on-current/off-current $\left(\mathrm{I}_{\mathrm{ON}} / \mathrm{I}_{\mathrm{OFF}}\right)$ values were extracted at a standard and small $\mathrm{V}_{D S}=-0.1 \mathrm{~V}$. The cross-sectional image of device structure was obtained from FEI Talos F200X high-resolution transmission electron microscope (TEM). The surface roughness of $\mathrm{HfO}_{2}$ films were obtained via Atomic Force Microscope (AFM) using DIMENSION 3100. The X-ray photoelectron spectroscopy (XPS) analyses of $\mathrm{HfO}_{2}$ films and $\mathrm{SnO}$ films were executed by Thermo Nexsa. The secondary ion mass spectrometry (SIMS) depth profiles of $\mathrm{Sn}$, Hf and $\mathrm{O}$ atoms were obtained by CAMECA IMS-6fE7.

\section{Results}

Figure 1a illustrates the top-view photograph of top-gate nanosheet SnO p-TFT, where the light-reflective $\mathrm{Al}$ metal-gate is on the top of the device. Figure $1 \mathrm{~b}$ depicts the crosssectional transmission electron microscope (TEM) image of the device structure with top Al-metal-gate, $\mathrm{HfO}_{2}$ gate-dielectric, and p-type channel $\mathrm{SnO}$ on $\mathrm{SiO}_{2} \mathrm{IMD}$. The thickness of $\mathrm{Al}, \mathrm{HfO}_{2}$, and nanosheet $\mathrm{SnO}$ is 50, 50, and $7 \mathrm{~nm}$, respectively.

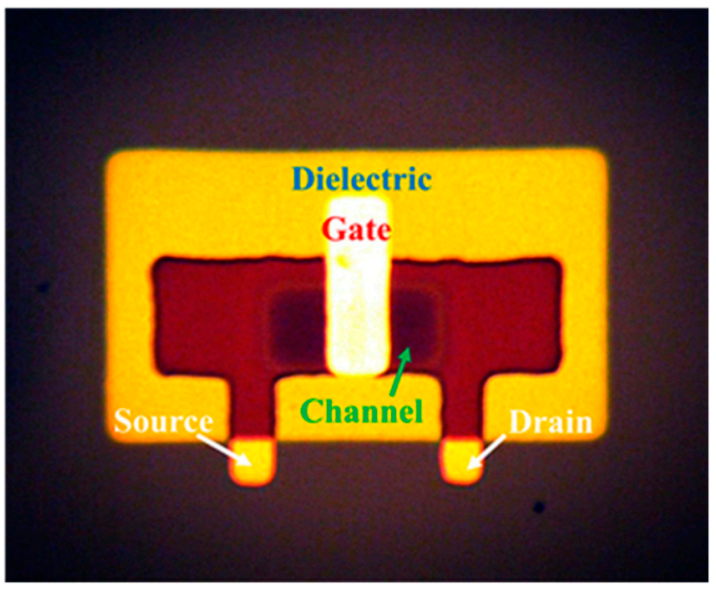

(a)

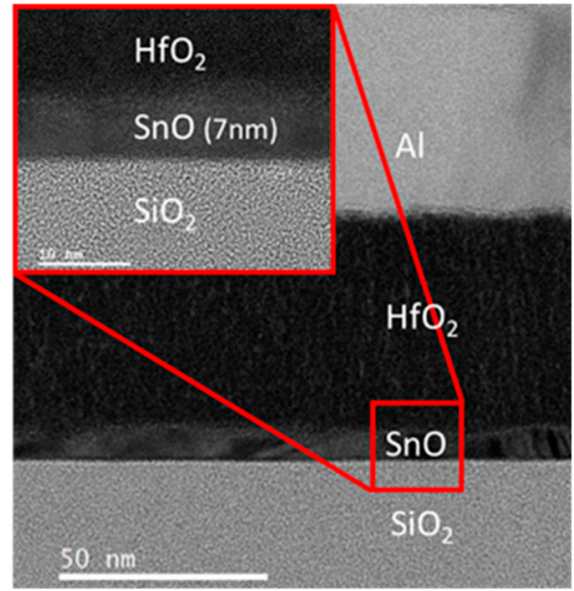

(b)

Figure 1. (a) top-view photograph and (b) cross-sectional TEM image of the top-gate nanosheet SnO p-TFT device. The "white"-color gate on top of the device is due to the light-reflective Al metal. 
The $O_{p p}$ is critical for top-gate nanosheet SnO p-TFT, where the SnO channel was made by sputtering from a metal $\mathrm{Sn}$ target under different $O_{p p}$ conditions. This is because the $\mathrm{SnO}$ can be oxidized into oxygen-rich $\mathrm{SnO}_{2}$ [16]. The $\mathrm{O}_{p p}$ can be expressed as follows:

$$
O_{p p}=\frac{P_{O_{2}}}{P_{O_{2}+} P_{A r}} \times 100 \% \text {, }
$$

where $P_{\mathrm{O}_{2}}$ and $P_{A r}$ are the pressures of $\mathrm{O}_{2}$ and $\mathrm{Ar}$ in a sputtering system, respectively. For comparison, the $O_{p p}$ values were adjusted to $14.2 \%, 25 \%$ and $33.3 \%$ during sputtering. Figure $2 \mathrm{a}, \mathrm{b}$ show the drain-source current versus gate-source voltage $\left(\left|I_{D S}\right|-V_{G S}\right)$ and $\mu_{F E^{-}}$ $V_{G S}$ characteristics of top-gate nanosheet $\mathrm{SnO}$ p-TFT devices, respectively, under different $\mathrm{O}_{p p}$ values. The top-gate p-type $\mathrm{SnO}$ device exhibits the highest $\mathrm{I}_{\mathrm{ON}}$ and the lowest leakage $\mathrm{I}_{\mathrm{OFF}}$ at the $25 \% \mathrm{O}_{p p}$ condition. The device with the best $\mathrm{I}_{\mathrm{ON}}$ and $\mathrm{I}_{\mathrm{OFF}}$ is also consistent with the highest $\mu_{F E}$. The $\mu_{F E}$ values were $1.5,4.4$ and $2.6 \mathrm{~cm}^{2} / \mathrm{Vs}$ at $O_{p p}$ of $14.2 \%, 25 \%$ and $33.3 \%$, respectively. Here the $\mu_{F E}$ values were obtained at the standard and a small $\mathrm{V}_{D S}$ of $-0.1 \mathrm{~V}$. Such abnormal $\mu_{F E}$ on $O_{p p}$ is ascribed to the following reasons. The device $\mu_{F E}$ increases with the increase in $O_{p p}$ from $14.2 \%$ to $25 \%$ due to the increased oxygen content in $\mathrm{SnO}_{\mathrm{x}}$, with $\mathrm{x} \leq 1$, and device performance degrades at a high $O_{p p}$ of $33.3 \%$ owing to the formation of oxygen-rich $\mathrm{SnO}_{\mathrm{x}}$, with $\mathrm{x}>1$. Under high $\mathrm{O}_{p p}, \mathrm{SnO}$ becomes n-type electron-conductive $\mathrm{SnO}_{2}$ [12-14], which lowers the hole $\mu_{F E}$ under negative $V_{G S}$.

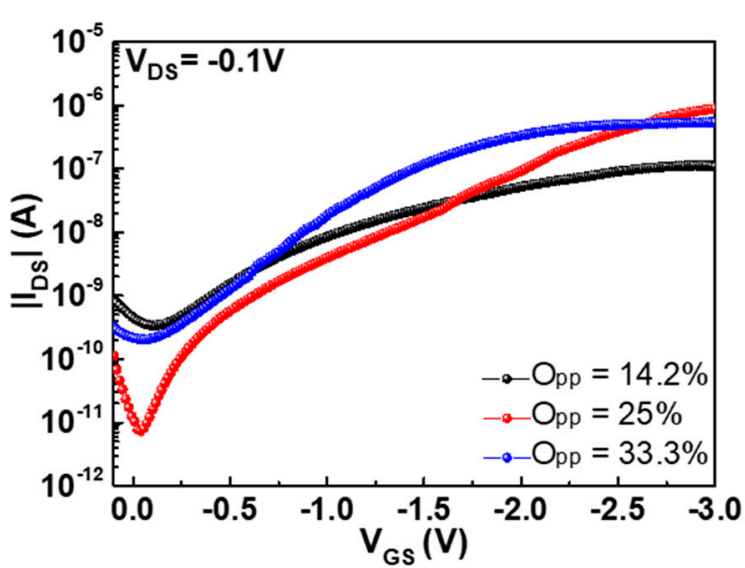

(a)

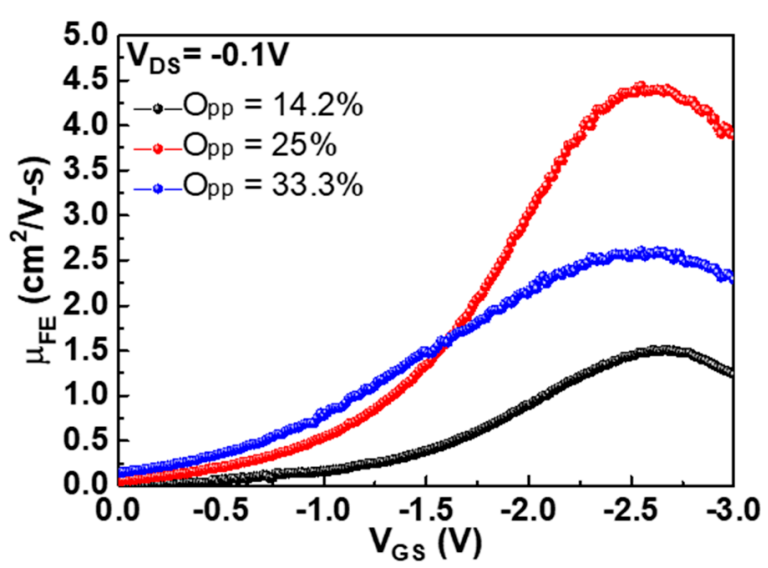

(b)

Figure 2. (a) $\left|I_{D S}\right|-V_{G S}$ and (b) $\mu_{F E^{-}} V_{G S}$ characteristics of top-gate nanosheet SnO p-TFTs with SnO channel deposited at different $\mathrm{O}_{p p}$ conditions. The SnO layer was annealed at $200{ }^{\circ} \mathrm{C}$ and $\mathrm{HfO}_{2}$ layer was annealed at $100{ }^{\circ} \mathrm{C}$.

The device integrity in top-gate nanosheet $\mathrm{SnO}$ p-TFT is also dependent on $\mathrm{HfO}_{2}$ annealing temperature. To avoid plasma damage to the $\mathrm{SnO}$ channel layer, the high- $\mathrm{HfO}_{2}$ gate dielectric was deposited using an e-beam evaporator and subjected to post-annealing at 100 and $200{ }^{\circ} \mathrm{C}$ for 30 min under $\mathrm{N}_{2}$ ambient. Here the SnO layers were deposited under $25 \% \mathrm{O}_{p p}$ and annealed at $200{ }^{\circ} \mathrm{C}$ under $\mathrm{N}_{2}$ ambient. Subsequently, the $\mathrm{HfO}_{2}$ were deposited and annealed at $100{ }^{\circ} \mathrm{C}$ or $200{ }^{\circ} \mathrm{C}$ under the $\mathrm{N}_{2}$ ambient. The $\left|I_{D S}\right|-V_{G S}$ and $\mu_{F E}-V_{G S}$ characteristics of SnO p-TFTs with 100 and $200{ }^{\circ} \mathrm{C}$ post-annealing are shown in Figure $3 \mathrm{a}, \mathrm{b}$, respectively. The $\mathrm{I}_{\mathrm{ON}} / \mathrm{I}_{\mathrm{OFF}}$ and $\mu_{F E}$ values of the $\mathrm{SnO} \mathrm{p}$-TFT at $100{ }^{\circ} \mathrm{C}$ postannealing are $1.2 \times 10^{5}$ and $4.4 \mathrm{~cm}^{2} / \mathrm{Vs}$, respectively, which are much better than those obtained at $200{ }^{\circ} \mathrm{C}: 4.6 \times 10^{2}$ and $1.44 \mathrm{~cm}^{2} / \mathrm{Vs}$, respectively. The $\mathrm{I}_{\mathrm{ON}} / \mathrm{I}_{\mathrm{OFF}}$ is even better than previous bottom-gate SnO p-TFT [16] possibly due to the thinner SnO channel used in this study, which slightly degrades the $\mu_{F E}$. A thin channel layer is needed to fully deplete the conductive oxide semiconductor $\mathrm{SnO}$, similar to the low $\mathrm{I}_{\mathrm{OFF}}$ using ultra-thin body Si-on-Insulator (SOI) and Fin field-effect transistor (FinFET). However, the small sub-10 
$\mathrm{nm}$-scale channel thickness can increase the interface roughness scattering and decrease the mobility.

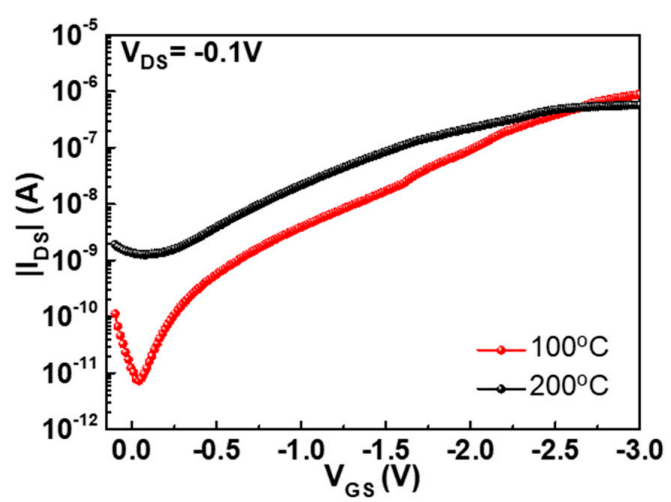

(a)

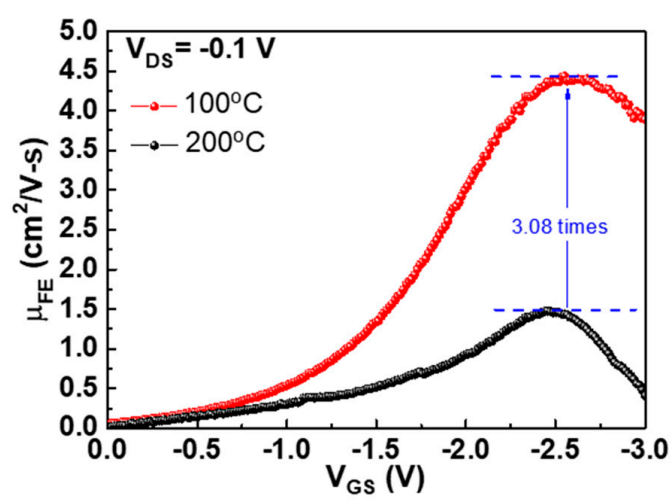

(b)

Figure 3. (a) $\left|I_{D S}\right|-V_{G S}$ and (b) $\mu_{F E^{-}} V_{G S}$ characteristics of top-gate nanosheet SnO TFT annealed at $100{ }^{\circ} \mathrm{C} \mathrm{N}_{2}$ ambient and $200{ }^{\circ} \mathrm{C} \mathrm{N}_{2}$ ambient.

To investigate the mechanism of such annealing temperature dependence, Figure $4 \mathrm{a}, \mathrm{b}$ plot the $\mathrm{I}_{D S}$ versus drain-source voltage $\left(I_{D S}-V_{D S}\right)$ and the gate-source current versus gate-source voltage $\left(\left|I_{G S}\right|-V_{G S}\right)$ characteristics of top-gate SnO p-TFTs, respectively, at annealing temperatures of 100 and $200{ }^{\circ} \mathrm{C}$. The p-TFT device at $100{ }^{\circ} \mathrm{C}$ annealing shows higher $\left|I_{D S}\right|$ than that at $200{ }^{\circ} \mathrm{C}$ annealing, corresponding to the higher $\mu_{F E}$ (Figure $3 \mathrm{~b}$ ). In normal case, a high post-annealing temperature of high- $\mathrm{K}$ gate dielectric is necessary to reduce the gate leakage current and improve the device performance. However, the measured $\left|I_{G S}\right|$ of $\mathrm{HfO}_{2} / \mathrm{SnO}$ p-TFT annealed at $200{ }^{\circ} \mathrm{C}$ shows one order of magnitude higher gate leakage than that in the device annealed at $100{ }^{\circ} \mathrm{C}$. The as-deposited $\mathrm{HfO}_{2}$ layer without annealing has too high gate leakage current due to defect conduction [41] and unsuitable for device application. To decrease the defect-conductive leakage current, even higher annealing temperature is required for metal-gate/high-k/Si CMOS $[39,42,43]$.

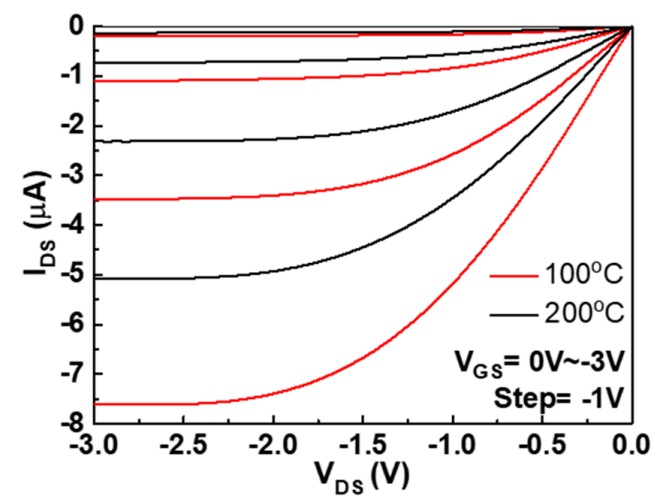

(a)

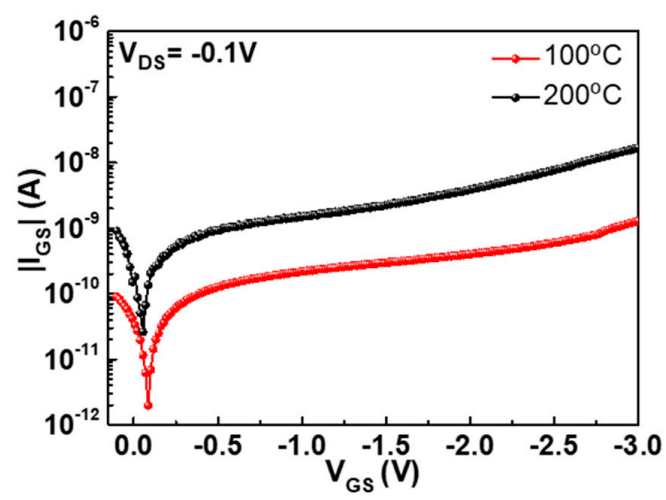

(b)

Figure 4. (a) $I_{D S}-V_{D S}$ and (b) $\left|I_{G S}\right|-V_{G S}$ characteristics of top-gate nanosheet SnO TFTs annealed at 100 and $200{ }^{\circ} \mathrm{C}$.

To further inspect the unusual annealing temperature dependence on device performance, material analysis of atomic force microscope (AFM), X-ray photoelectron spectroscopy (XPS), and secondary ion mass spectrometry (SIMS) were performed. In Figure S1, the surface roughness of the $50 \mathrm{~nm} \mathrm{HfO}_{2}$ films annealed at $100{ }^{\circ} \mathrm{C}, 200{ }^{\circ} \mathrm{C}$ and $400{ }^{\circ} \mathrm{C}$ were analyzed through AFM. The root mean square values of surface roughness show slightly decrease along with the increasement of the annealing temperature. The $\mathrm{HfO}_{2}$ dielectric 
with different annealing temperatures were also analyzed by XPS. As shown in Figure S2, the binding energies of Hf-O and non-lattice $\mathrm{O}$ were $530 \mathrm{eV}$ and $531.3 \mathrm{eV}$, respectively. The peak intensity of non-lattice $\mathrm{O}$ was related to the defects in $\mathrm{HfO}_{2}$ dielectric, which decreased with increasing post-annealing temperature. From the AFM and XPS analysis, the good device performance at $100{ }^{\circ} \mathrm{C}$ annealing is not related to the tiny difference of $\mathrm{HfO}_{2}$ layer.

To further investigate the $O_{p p}$ effect on chemical composition of the SnO layer, the XPS analyses on channel $\mathrm{SnO}$ were performed at the $\mathrm{O}_{p p}$ of $14.2 \%, 25 \%$ and $33.3 \%$. The $\mathrm{HfO}_{2}$ layer of $\mathrm{HfO}_{2} / \mathrm{SnO}$ stack were etched before the XPS analysis. The XPS data are depicted in Figure 5. The XPS spectra can be deconvolved into three curves from the $\mathrm{Sn}^{2+} \mathrm{O}, \mathrm{Sn}^{4+} \mathrm{O}_{2}$ and $\mathrm{Sn}^{0}$ signals, with their corresponding energies of $486.8,486$ and $484.4 \mathrm{eV}$, respectively. The composition $x$ values of $\mathrm{SnO}_{\mathrm{x}}$ deposited at $\mathrm{O}_{p p}=14.2 \%, 25 \%$ and $33.3 \%$ were $0.8,0.95$ and 1.3, respectively, which explains well the measured electrical data in Figure 2.

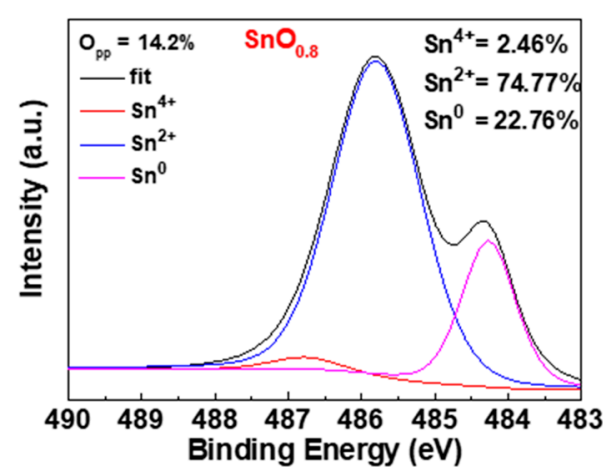

(a)

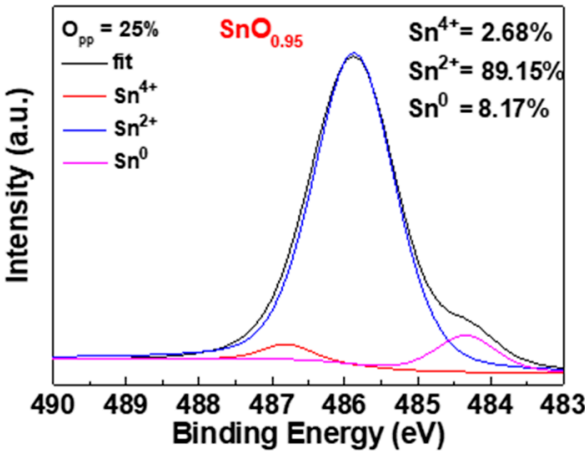

(b)

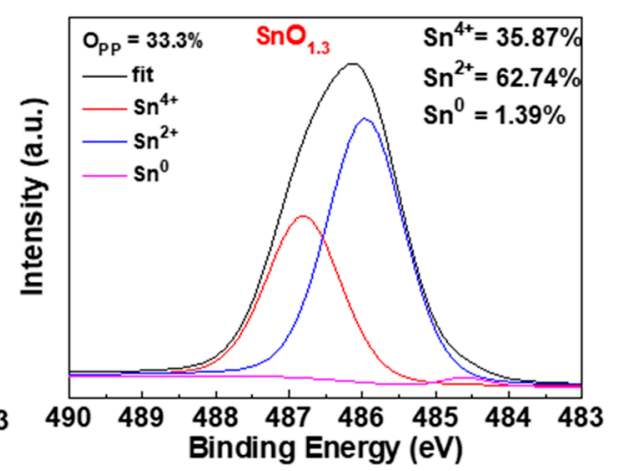

(c)

Figure 5. The $\mathrm{Sn} 3 \mathrm{~d}_{5 / 2}$ spectra of $\mathrm{SnO}$ films deposited at $O_{p p}$ of (a) $14.2 \%$, (b) $25 \%$ and (c) $33.3 \%$.

Figure 6a-c show the SIMS profiles of $\mathrm{Hf}, \mathrm{Sn}$ and $\mathrm{O}$ atoms from the $\mathrm{HfO}_{2} / \mathrm{SnO}$ device structure annealed at 100,200 and $400{ }^{\circ} \mathrm{C}$, respectively. Increasing the annealing temperature from 100 to $400{ }^{\circ} \mathrm{C}$ led to significant $\mathrm{Sn}$ diffusion from $\mathrm{SnO}$ into $\mathrm{HfO}_{2}$. This is attributed to the weak $\mathrm{Sn}-\mathrm{O}$ band enthalpy [38], even though it also leads to high hole mobility $[15,16]$ :

$$
\mathrm{SnO} \rightarrow \mathrm{Sn}^{2+}+\mathrm{O}^{2-}
$$

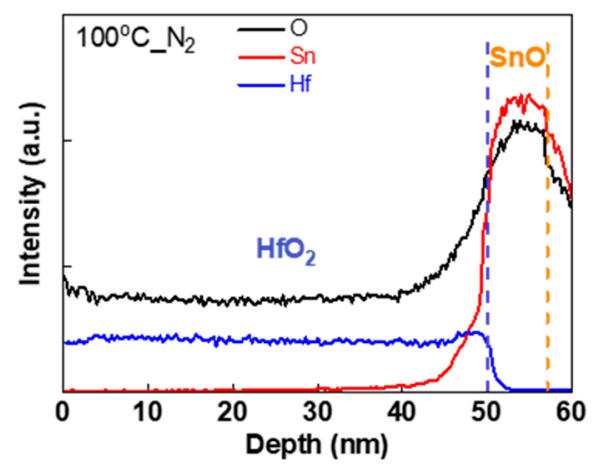

(a)

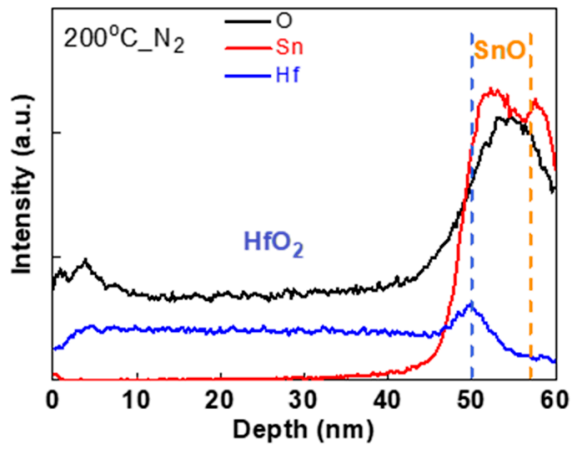

(b)

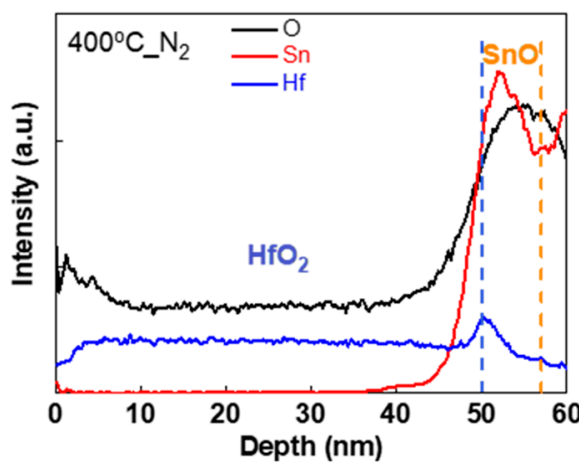

(c)

Figure 6. SIMS depth profiles of $\mathrm{HfO}_{2} / \mathrm{SnO}$ stack annealed at (a) 100 , (b) 200 and (c) $400{ }^{\circ} \mathrm{C} \mathrm{N}_{2}$ ambient.

The charged $\mathrm{Sn}^{2+}$ can diffuse into $\mathrm{HfO}_{2}$, create vacancies at elevated temperatures, and, together with charged $\mathrm{O}^{2-}$ ions, allow $\mathrm{HfO}_{x}$ diffusion into the $\mathrm{SnO}$ layer at $200{ }^{\circ} \mathrm{C}$ annealing temperature. The inter-diffusion of $\mathrm{Sn}$ and $\mathrm{Hf}$ atoms and the formed vacancies and charged ions further degrade the $\mathrm{HfO}_{2}$ gate-dielectric and $\mathrm{HfO}_{2} / \mathrm{SnO}$ interface that 
cause poor $\left|I_{G S}\right|, \mu_{F E}, \mathrm{I}_{\mathrm{ON}}$, and $\mathrm{I}_{\mathrm{OFF}}$. The amount of Hf diffusion into the SnO layer at $400{ }^{\circ} \mathrm{C}$ annealing temperature can be calculated by the area within SnO layer in Figure $6 \mathrm{c}$, which is 1.15 times higher than the $\mathrm{HfO}_{2} / \mathrm{SnO}$ annealed at $200^{\circ} \mathrm{C}$. The $\mathrm{Sn}$ atoms diffused into $\mathrm{HfO}_{2}$ layer at $400{ }^{\circ} \mathrm{C}$ were 1.14 times more than the $\mathrm{HfO}_{2} / \mathrm{SnO}$ annealed at $200{ }^{\circ} \mathrm{C}$. Thus, the higher post-annealing temperature will cause more inter-diffusion between $\mathrm{HfO}_{2}$ and $\mathrm{SnO}$.

The diffused $\mathrm{Sn}^{2+}$ can behave as trap states in $\mathrm{HfO}_{2}$ gate dielectric, provide extra transport paths for the carriers, and lead to higher gate leakage current (Figure 4b). To understand the conduction mechanism of gate leakage current, the measured data were fitted with various mechanisms. As shown in Figure 7a, the measured $\left|I_{G S}\right|-V_{G S}$ fits well with the hopping conduction [44-47], under an electric field $(E)$ of $<0.25 \mathrm{MV} / \mathrm{cm}$, for 100 and $200{ }^{\circ} \mathrm{C}$ annealed top-gate $\mathrm{SnO}$ p-TFTs, where the slope of $\ln \left(\left|\mathrm{J}_{G S}\right|\right)-E$ is 5.72 and 4.91, respectively. The hopping conduction mechanism is expressed as [45]:

$$
|\mathrm{J}|=q a \mathrm{n} v \times \exp \left[\frac{q a E}{k T}-\frac{E_{a}}{k T}\right],
$$

where $\mathrm{J}, q, a, \mathrm{n}, v$, and $E_{a}$ are the current density, electron charge, mean hopping distance, carrier concentration, thermal vibration frequency of carriers at trap states, and activation energy, respectively. The hopping distances of 100 and $200{ }^{\circ} \mathrm{C}$ annealed devices calculated from Equation (3) are 1.48 and $1.27 \mathrm{~nm}$, respectively. The smaller hopping distance is ascribed to the $\mathrm{Sn}$ diffusion in $\mathrm{HfO}_{2}$, which increases the gate leakage $J_{G S}$. The mechanism of poor gate leakage current and interface at high annealing temperature is depicted schematically in Figure $7 \mathrm{~b}$. The trap-induced hopping conduction causes high $\left|I_{G S}\right|$. The degraded interface by Sn and Hf inter-diffusion and created vacancies increase the hole scattering from the source to drain, thus lowering the important $\mathrm{I}_{\mathrm{ON}}$ and $\mu_{F E}$. The created vacancies also increase the $\mathrm{I}_{\mathrm{OFF}}$ through defect conduction. The device performance can be further evaluated by the $\left|I_{D S}\right|-V_{G S}$ hysteresis curves. The defect density formed by hysteresis curves, under forward and reverse sweep between 0 to $-3 \mathrm{~V}$, are $1.5 \times 10^{12}$ and $5.4 \times 10^{12} \mathrm{~cm}^{-2}$ for device annealed at 100 and $200{ }^{\circ} \mathrm{C}$, respectively. This result is consistent to our conclusion: the higher post-annealing temperature creates more defects in the $\mathrm{HfO}_{2} / \mathrm{SnO}$ gate capacitor, which leads to higher gate leakage current, lower hole mobility, and poorer hysteresis than the one annealed at lower $100{ }^{\circ} \mathrm{C}$ temperature.

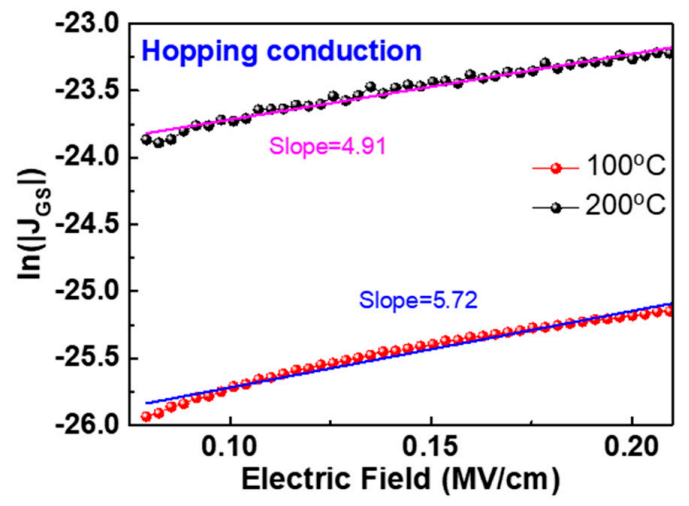

(a)

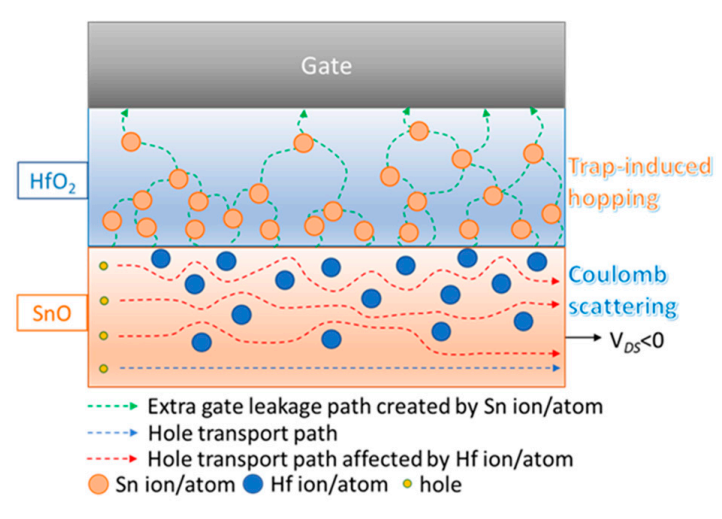

(b)

Figure 7. (a) $\left|I_{G S}\right|-V_{G S}$ characteristics of top-gate nanosheet $\mathrm{HfO}_{2} / \mathrm{SnO}$ p-TFTs annealed at 100 and $200{ }^{\circ} \mathrm{C}$. (b) Schematic diagram to show gate leakage and inter-diffusion of top-gate SnO TFT device annealed at $200{ }^{\circ} \mathrm{C}$.

The sub-threshold slope is related to interface trap, which can be calculated [48]:

$$
\mathrm{SS}=\frac{K T}{q} \times \ln 10 \times\left(1+\frac{C_{d e p}+C_{i t}}{C_{o x}}\right)
$$


where the $C_{d e p}, C_{i t}$ and $C_{o x}$ are the depletion capacitance, interface trap capacitance and gate dielectric capacitance, respectively. The interface trap density $\left(D_{i t}\right)$ is $2.5 \times 10^{13} \mathrm{eV}^{-1} \mathrm{~cm}^{-2}$ that is higher than the metal-gate/high- $\mathrm{K} / \mathrm{Si}$ CMOS. Therefore, the hump of sub-threshold $\left|I_{D S}\right|-V_{G S}$ curve in Figure 2 is due to the charge modulation from the interface traps [49]. In comparison with $\mathrm{SnO}$ atomic density of $2.9 \times 10^{22}$ atoms $/ \mathrm{cm}^{3}$ or sheet atomic density of $9.4 \times 10^{14}$ atoms $/ \mathrm{cm}^{2}$, the $\mathrm{D}_{\mathrm{it}}$ is only $2.7 \%$ of the sheet atoms of $\mathrm{SnO}$. Thus, the electronic measurement is highly sensitive to defects compared with other measurements.

The $\mu_{F E}$ data increase to a peak value and decrease with increasing gate field. The detailed physical analysis in oxide semiconductor transistor is not reported yet. However, such hole mobility dependence is generally observed in $\mathrm{SiO}_{2} / \mathrm{Si}$ [50], high- $\mathrm{K} / \mathrm{Si}$ [51-53], $\mathrm{SiO}_{2} / \mathrm{SiGe}$ [54], high-K/SiGe [55] and high-K/Ge [56] p-MOSFETs. Because the $\mathrm{Si}$, SiGe, Ge and $\mathrm{SnO}$ are all semiconductors and have the similar valance band structure, the decreased mobility at high electric field may be due to the similar mechanisms of phonon and interface roughness scatterings [57].

The $\mathrm{La}_{2} \mathrm{O}_{3}$ can achieve the excellent performance of low leakage current and high$\kappa$ value $[55,58,59]$, but the moisture degradation is stronger than the $\mathrm{HfO}_{2}$ and $\mathrm{ZrO}_{2}$. The $\mathrm{ZrO}_{2}$ [60] has a higher $\mathrm{k}$ value than $\mathrm{HfO}_{2}$ once crystallized, which is widely used for dynamic random-access memory (DRAM) capacitor. For gate dielectric application, orientation-independent amorphous material like conventional $\mathrm{SiO}_{2}$ is needed [61]. The $\mathrm{TiO}_{2}$ has the highest $\mathrm{k}$ value but suffers from the small energy bandgap and high leakage current [62]. Thus, the $\mathrm{TiO}_{2}$ is generally added to other high- $\mathrm{K}$ dielectric to increase the overall $\mathrm{k}$ value [63]. The $\mathrm{Al}_{2} \mathrm{O}_{3}$ has been used for gate dielectric due to its excellent stability [40], but suffers from relatively lower $\mathrm{k}$ value than $\mathrm{HfO}_{2}$. Therefore, the $\mathrm{HfO}_{2}$ is used for CMOS application and also for this work.

To inspect the stability of the top-gate SnO TFT devices, the devices were measured at as-fabricated and after retention in air ambient for two months, as depicted in Figure 8. In comparison with the conventional bottom-gate structure, such top-gate device shows huge stability improvement after retention in air [32], which is due to fully covered channel layer by metal-gate and gate-dielectric. Therefore, both the 100 and $200{ }^{\circ} \mathrm{C}$ annealed top-gate transistors show only slight degradation after exposure in air for two months. The top-gate $\mathrm{HfO}_{2} / \mathrm{SnO}$ p-TFT has slightly lower hole $\mu_{F E}$ of $4.4 \mathrm{~cm}^{2 /} \mathrm{Vs}$ than our previously reported $7.6 \mathrm{~cm}^{2} / \mathrm{Vs}$ of bottom-gate $\mathrm{HfO}_{2} / \mathrm{SnO}$ device, which is attributed to the $\mathrm{HfO}_{2} / \mathrm{SnO}$ interdiffusion. Because of the larger SS of top-gate device than the bottom-gate one with the same $\mathrm{HfO}_{2}$ and $\mathrm{SnO}$, the $\mathrm{HfO}_{2} / \mathrm{SnO}$ interface degradation is confirmed from Equation (4).

Table 1 presents a comparison of the essential device characteristics of top-gate $\mathrm{SnO} p$ TFTs [11,33-35] The merits of this work are the highest $\mu_{F E}$ of $4.4 \mathrm{~cm}^{2} / \mathrm{Vs}$, largest $\mathrm{I}_{\mathrm{ON}} / \mathrm{I}_{\mathrm{OFF}}$ of $1.2 \times 10^{5}$, and sharpest SS of $526 \mathrm{mV} /$ decade reported to date at fabrication temperatures of only $100-200^{\circ} \mathrm{C}$. This device thus has high potential to be integrated into the IMD layer of Si chips for monolithic 3D and brain-mimicking IC applications.

Table 1. The device performances of various top-gate $\mathrm{SnO}$ p-TFTs.

\begin{tabular}{|c|c|c|c|c|c|c|}
\hline Reference & $\begin{array}{c}\text { SnO } \\
\text { Thickness (nm) }\end{array}$ & $\begin{array}{c}\text { Gate Insulator } \\
\text { Materials }\end{array}$ & $\begin{array}{c}\mu_{F E}\left(\mathrm{~cm}^{2} / \mathrm{V} \cdot \mathrm{s}\right) \\
@ \mathrm{~V}_{D S}(\mathrm{~V})\end{array}$ & $\mathbf{I}_{\mathrm{ON}} / \mathbf{I}_{\mathrm{OFF}}$ & $\begin{array}{c}\text { SS } \\
\text { (mV/Decade) }\end{array}$ & $\begin{array}{c}\text { Process } \\
\text { Temp. }\left({ }^{\circ} \mathrm{C}\right)\end{array}$ \\
\hline 11 & 15.4 & $\mathrm{Y}_{2} \mathrm{O}_{3}$ & $0.05 @-1$ & $10^{2}$ & - & 250 \\
\hline 33 & 20 & $\mathrm{Al}_{2} \mathrm{O}_{3}$ & $1.3 @-2$ & $10^{2}$ & 7 & 575 \\
\hline 34 & 15 & $\mathrm{HfO}_{2}$ & $0.71 @-1$ & $1.6 \times 10^{3}$ & 1.6 & 200 \\
\hline 35 & 30 & $\mathrm{P}(\mathrm{VDF}-\mathrm{TrFE})$ & $2.7 @-1$ & $2.2 \times 10^{2}$ & 4 & 200 \\
\hline This work & 7 & $\mathrm{HfO}_{2}$ & $4.4 @-0.1$ & $2 \times 10^{5}$ & 0.526 & 200 \\
\hline
\end{tabular}




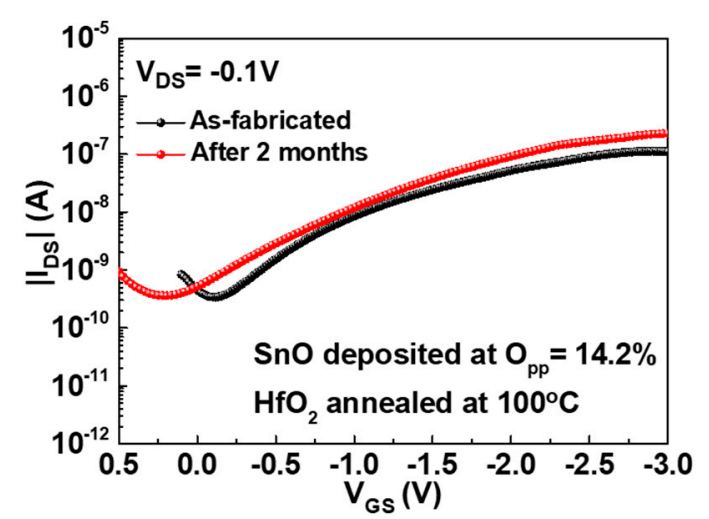

(a)

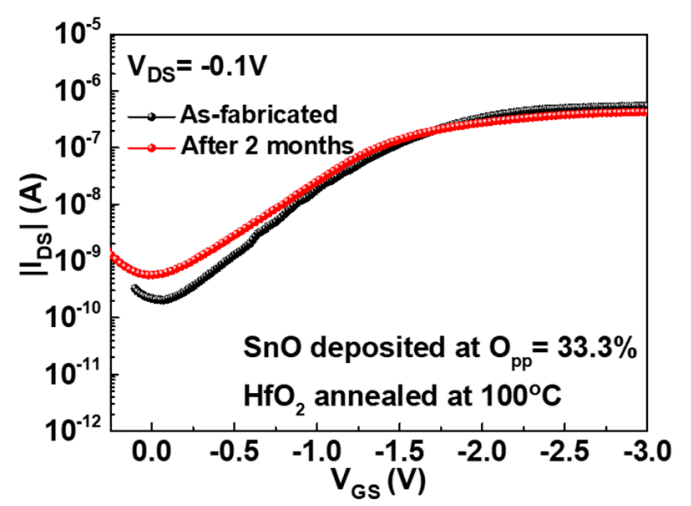

(c)

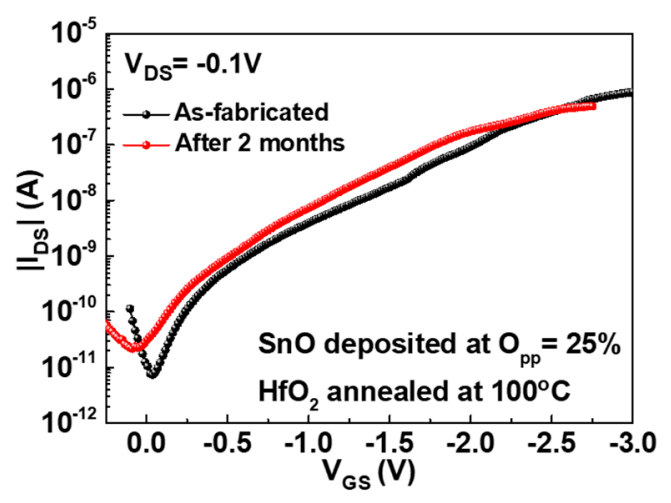

(b)

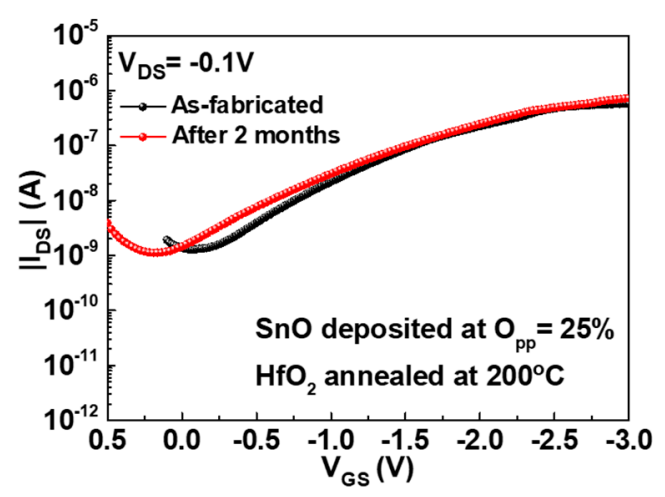

(d)

Figure 8. The $\left|\mathrm{I}_{D S}\right|-V_{G S}$ characteristics of the top-gate nanosheet SnO TFT devices with (a) SnO deposited at $O_{p p}=14.2 \%$ and $\mathrm{HfO}_{2}$ annealed at $100{ }^{\circ} \mathrm{C}$, (b) SnO deposited at $\mathrm{O}_{p p}=25 \%$ and $\mathrm{HfO}_{2}$ annealed at $100{ }^{\circ} \mathrm{C}$, (c) SnO deposited at $\mathrm{O}_{p p}=33.3 \%$ and $\mathrm{HfO}_{2}$ annealed at $100{ }^{\circ} \mathrm{C}$, and (d) $\mathrm{SnO}$ deposited at $\mathrm{O}_{p p}=25 \%$ and $\mathrm{HfO}_{2}$ annealed at $200{ }^{\circ} \mathrm{C}$. The devices were measured at as-fabricated and after 2 months' exposure to air ambient.

\section{Conclusions}

While $\mathrm{SnO}$ has the advantage of high hole mobility, it also has low bond enthalpy. The key factor for good device integrity of top-gate $\mathrm{HfO}_{2} / \mathrm{SnO}$ p-TFT is to maintain the low process temperature, which can preserve good $\mathrm{HfO}_{2} / \mathrm{SnO}$ interface. Such a lowtemperature fabrication $\left(100-200{ }^{\circ} \mathrm{C}\right)$ and excellent device performance are crucial for monolithic 3D and brain-mimicking ICs made on the backend IMD layers of Si chips.

Supplementary Materials: The following are available online at https:/ / www.mdpi.com/2079-499 1/11/1/92/s1, Figure S1: The surface roughness analysis of $\mathrm{HfO}_{2}$ annealed at (a) $100{ }^{\circ} \mathrm{C}$, (b) $200{ }^{\circ} \mathrm{C}$ and (c) $400{ }^{\circ} \mathrm{C}$ through AFM. Figure S2: The $\mathrm{O}_{1 \mathrm{~s}}$ spectra of $\mathrm{HfO}_{2}$ films annealed at (a) $100{ }^{\circ} \mathrm{C}$, (b) $200{ }^{\circ} \mathrm{C}$ and (c) $400{ }^{\circ} \mathrm{C}$.

Author Contributions: T.J.Y. did the experiments; A.C. is the principle investigator (PI) to monitor the project; V.G. is the co-PI for this work. All authors reviewed the manuscript. All authors have read and agreed to the published version of the manuscript.

Funding: This research was funded by Ministry of Science and Technology of Taiwan, project no. 107-2221-E-009-092-MY3.

Institutional Review Board Statement: Not applicable.

Informed Consent Statement: Not applicable.

Data Availability Statement: The data presented in this study are available on request from the corresponding author. The data are not publicly available due to privacy. 
Acknowledgments: We would also like to thank Y. R. Wang for assisting the device fabrication during her master degree study.

Conflicts of Interest: The authors declare no conflict of interest.

\section{References}

1. Fortunato, E.; Barquinha, P.; Martins, R. Oxide semiconductor thin-film transistors: A review of recent advances. Adv. Mater. 2012, 24, 2945-2986. [CrossRef] [PubMed]

2. Nomura, K.; Ohta, H.; Takagi, A.; Kamiya, T.; Hirano, M.; Hosono, H. Room-temperature fabrication of transparent flexible thin-film transistors using amorphous oxide semiconductors. Nature 2004, 432, 488-492. [CrossRef] [PubMed]

3. Su, N.C.; Wang, S.J.; Huang, C.C.; Chen, Y.H.; Huang, H.Y.; Chiang, C.K.; Chin, A. Low-voltage-driven flexible InGaZnO thin-film transistor with small subthreshold swing. IEEE Electron. Device Lett. 2010, 31, 680-682.

4. Petti, L.; Munzenrieder, N.; Vogt, C.; Faber, H.; Buthe, L.; Cantarella, G.; Bottacchi, F.; Anthopoulos, T.D.; Troster, G. Metal oxide semiconductor thin-film transistors for flexible electronics. Appl. Phys. Rev. 2016, 3, 021303. [CrossRef]

5. Shih, C.W.; Chin, A. Remarkably High mobility thin-film transistor on flexible substrate by novel passivation material. Sci. Rep. 2017, 7, 1147. [CrossRef] [PubMed]

6. Yin, X.; Deng, S.; Li, G.; Zhong, W.; Chen, R.; Li, G.; Yeung, F.S.Y.; Wong, M.; Kwok, H.S. Low Leakage Current Vertical Thin-Film Transistors with InSnO-stabilized ZnO Channel. IEEE Electron. Device Lett. 2020, 41, 248-251. [CrossRef]

7. Ohshima, H.; Morozumi, S. Future trends for TFT integrated circuits on glass substrates. In Proceedings of the International Technical Digest on Electron Devices Meeting, Washington, DC, USA, 3-6 December 1989.

8. Liu, A.; Liu, G.; Zhu, H.; Song, H.; Shin, B.; Fortunato, E.; Martin, R.; Shan, F. Water-induced scandium oxide dielectric for low-operating voltage $\mathrm{n}$ - and p-type metal-oxide thin-film transistors. Adv. Funct. Mater. 2015, 25, 7180-7188. [CrossRef]

9. Liang, L.Y.; Cao, H.T.; Chen, X.B.; Liu, Z.M.; Zhuge, F.; Luo, H.; Li, J.; Lu, Y.C.; Lu, W. Ambipolar inverters using SnO thin-film transistors with balanced electron and hole mobilities. Appl. Phys. Lett. 2012, 100, 263502. [CrossRef]

10. Lee, C.H.; Sazonov, A.; Nathan, A. High mobility n-channel and p-channel nanocrystalline silicon thin-film transistors. In Proceedings of the IEEE International Electron Devices Meeting, IEDM Technical Digest, Washington, DC, USA, 5 December 2005.

11. Nomura, K.; Kamiya, T.; Hosono, H. Ambipolar oxide thin-film transistor. Adv. Mater. 2011, 23, 3431-3434. [CrossRef]

12. Shih, C.W.; Chin, A. New material transistor with record-high field-effect mobility among wide-band-gap semiconductors. ACS Appl. Mater. Interfaces 2016, 8, 19187-19191. [CrossRef]

13. Shih, C.W.; Chin, A.; Lu, C.F.; Su, W.F. Remarkably high mobility ultra-thin-film metal-oxide transistor with strongly overlapped orbitals. Sci. Rep. 2016, 6, 19023. [CrossRef] [PubMed]

14. Shih, C.W.; Yen, T.J.; Chin, A.; Lu, C.F.; Su, W.F. Low-temperature processed tin oxide transistor with ultraviolet irradiation. IEEE Electron. Device Lett. 2019, 40, 909-912. [CrossRef]

15. Shih, C.W.; Chin, A.; Lu, C.F.; Yi, S.H. Extremely high mobility ultra-thin metal-oxide with $\mathrm{ns}^{2} \mathrm{np}^{2}$ configuration. In Proceedings of the 2015 IEEE International Electron Devices Meeting (IEDM), Washington, DC, USA, 7-9 December 2015; pp. 145-148.

16. Shih, C.W.; Chin, A.; Lu, C.F.; Su, W.F. Remarkably high hole mobility metal-oxide thin-film transistors. Sci. Rep. 2018, 8, 889. [CrossRef] [PubMed]

17. Chin, A.; Yen, T.J.; Shih, C.W.; Chen, Y.D. High mobility metal-oxide devices for display SoP and 3D brain-mimicking IC. Proc. Int. Disp. Workshops 2019, 26, 455-457. [CrossRef]

18. Chin, A.; Chen, Y.D. Technologies toward three-dimensional brain-mimicking IC architecture. In Proceedings of the 2019 Electron Devices Technology and Manufacturing Conference (EDTM), Singapore, 12-15 March 2019; pp. 472-474.

19. Kwon, J.; Takeda, Y.; Shiwaku, R.; Tokito, S.; Cho, K.; Jung, S. Three-dimensional monolithic integration in flexible printed organic transistors. Nat. Commun. 2019, 10, 54. [CrossRef]

20. Sisman, Z.; Bolat, S.; Okyay, A.K. Atomic layer deposition for vertically integrated ZnO thin film transistors: Toward 3D High packing density thin film electronics. Phys. Status Solidi C 2017, 14, 1700128.

21. Felfel, A.M.; Datta, K.; Dutt, A.; Veluri, H.; Zaky, A.; Thean, A.V.Y.; Aly, M.M.S. Quantifying the benefits of monolithic 3D computing systems enabled by TFT and RRAM. In Proceedings of the 2020 Design, Automation \& Test in Europe Conference \& Exhibition (DATE), Grenoble, France, 9-13 March 2020; pp. 43-48.

22. Choi, S.H.; Jang, J.H.; Kim, J.J.; Han, M.K. Low-temperature organic (CYTOP) passivation for improvement of electric characteristics and reliability in IGZO TFTs. IEEE Electron. Device Lett. 2012, 33, 381-383. [CrossRef]

23. Chowdhury, M.D.H.; Mativenga, M.; Um, J.G.; Mruthyunjaya, R.K.; Heiler, G.N.; Tredwell, T.J.; Jang, J. Effect of SiO 2 and $\mathrm{SiO}_{2} / \mathrm{SiN}_{\mathrm{x}}$ passivation on the stability of amorphous indium-gallium zinc-oxide thin-film transistors under high humidity. IEEE Trans Electron. Devices 2015, 62, 869-874. [CrossRef]

24. Park, J.; Song, I.; Kim, S.; Kim, S.; Kim, C.; Lee, J.; Lee, H.; Lee, E.; Yin, H.; Kim, K.K.; et al. Self-aligned top-gate amorphous gallium indium zinc oxide thin film transistors. Appl. Phys. Lett. 2008, 93, 053501. [CrossRef]

25. King, T.J. Trends in polycrystalline-silicon thin-film transistor technology for AMLCD's. In Proceedings of the Second International Workshop on Active Matrix Liquid Crystal Displays, Bethlehem, PA, USA, 25-26 September 1995; pp. 80-86.

26. Wang, Z.; Nayak, P.K.; Caraveo-Frescas, J.A.; Alshareef, H.N. Recent developments in p-type oxide semiconductor materials and devices. Adv. Mater. 2016, 28, 3831-3892. [CrossRef] 
27. Caraveo-Frescas, J.A.; Nayak, P.K.; Al-Jawhari, H.A.; Granato, D.B.; Schwingenschlogl, U.; Alshareef, H.N. Record mobility in transparent p-type tin monoxide films and devices by phase engineering. ACS Nano 2013, 7, 5160-5167. [CrossRef] [PubMed]

28. Batzill, M.; Diebold, U. The surface and materials science of tin oxide. Prog. Surf. Sci. 2005, 79, 47-154. [CrossRef]

29. Fortunato, E.; Barros, R.; Barquinha, P.; Figueiredo, V.; Park, S.H.K.; Hwang, C.S.; Rodrigo, M. Transparent p-type SnO ${ }_{x}$ thin film transistors produced by reactive rf magnetron sputtering followed by low temperature annealing. Appl. Phys. Lett. 2010, 97, 052103-052105. [CrossRef]

30. Pham, H.P.; Nguyen, T.H.Y.; Nguyen, A.H.T.; Vo, N.T.; Thuy, T.G.L.; Nguyen, H.H.; Hoa, H.T.M.; Tran, Q.T. Effects of substrate temperature on characteristics of the p-type Ag-doped $\mathrm{SnO}_{\mathrm{x}}$ thin films prepared by reactive DC magnetron sputtering. J. Photoch. Photobio. A Chem. 2020, 388, 112157. [CrossRef]

31. Li, Y.; Xin, Q.; Du, L.; Qu, Y.; Li, H.; Kong, X.; Wang, Q.; Song, A. Extremely sensitive dependence of SnO $\mathrm{O}_{\mathrm{x}}$ film properties on sputtering power. Sci. Rep. 2016, 6, 36183. [CrossRef]

32. Yen, T.J.; Chin, A.; Gritsenko, V. High performance top-gate thin film transistor with an ultra-thin channel layer. Nanometerials 2020, 10, 2145. [CrossRef]

33. Ogo, Y.; Hiramatsu, H.; Nomura, K.; Yanagi, H.; Kamiya, T.; Masahiro, H.; Hosono, H. P-channel thin-film transistor using p-type oxide semiconductor, SnO. Appl. Phys. Lett. 2008, 93, 032113. [CrossRef]

34. Cheng, I.C.; Hsu, S.M.; Lin, W.C.; Chen, J.Z. Influence of mechanical bending strain on bias-stress stability of flexible top-gate p-type SnO TFTs. Proc. SPIE 2020, 11304, 1-6.

35. Khan, M.A.; Caraveo-Frescas, J.A.; Alshareef, H.N. Hybrid dual gate ferroelectric memory for multilevel information storage. Org. Electron. 2015, 16, 9-17. [CrossRef]

36. Hautier, G.; Miglio, A.; Ceder, G.; Rignanese, G.-M.; Gonze, X. Identification and design principles of low hole effective mass p-type transparent conducting oxides. Nat. Commun. 2013, 4, 2292. [CrossRef]

37. Nakano, Y.; Saeki, S.; Morikawa, T. Optical bandgap widening of p-type $\mathrm{Cu}_{2} \mathrm{O}$ films by nitrogen doping. Appl. Phys. Lett. 2009, 94, 022111. [CrossRef]

38. Wu, C.H.; Hung, B.F.; Chin, A.; Wang, S.J.; Chen, W.J.; Wang, X.P.; Li, M.F.; Zhu, C.; Jin, Y.; Tao, H.J.; et al. High temperature stable $\left[\mathrm{Ir}_{3} \mathrm{Si}-\mathrm{TaN}\right] / \mathrm{HfLaON}$ CMOS with large work-function difference. In Proceedings of the 2006 International Electron Devices Meeting, San Francisco, CA, USA, 11-13 December 2006; pp. 617-620.

39. Zhu, S.; Yu, H.Y.; Whang, S.J.; Chen, J.H.; Shen, C.; Zhu, C.; Lee, S.J.; Li, M.F.; Chan, D.S.H.; Yoo, W.J.; et al. Schottky-barrier S/D MOSFETs with high-k gate dielectrics and metal gate electrode. IEEE Electron. Device Lett. 2004, 25, 268-270. [CrossRef]

40. Zhu, S.; Li, R.; Lee, S.J.; Li, M.F.; Du, A.; Singh, J.; Zhu, C.; Chin, A.; Hwong, D.L. Germanium pMOSFETs with Schottky-barrier Germanide S/D, high-K gate dielectric and metal gate. IEEE Electron. Device Lett. 2005, 26, 81-83.

41. Islamov, D.R.; Gritsenko, V.A.; Rzhanov, A.V.; Cheng, C.H.; Chin, A. Bipolar conductivity in amorphous HfO 2 . Appl. Phys. Lett. 2001, 99, 072109. [CrossRef]

42. Chin, A.; Liao, C.C.; Lu, C.H.; Chen, W.J.; Tsai, C. Device and reliability of high- $\mathrm{Al}_{2} \mathrm{O}_{3}$ gate dielectric with good mobility and low $\mathrm{D}_{\mathrm{it}}$. VLSI Symp. Tech. Digest. 1999, 135-136. [CrossRef]

43. Cheng, C.F.; Wu, C.H.; Su, N.C.; Wang, S.J.; McAlister, S.P.; Chin, A. Very low $\mathrm{V}_{\mathrm{t}}[\mathrm{Ir}-\mathrm{Hf}] / \mathrm{HfLaO}$ CMOS using novel self-aligned low temperature shallow junctions. In Proceedings of the 2007 IEEE International Electron Devices Meeting, Washington, DC, USA, 10-12 December 2007; pp. 333-336.

44. Wang, Z.; Yu, H.; Tran, X.A.; Fang, Z.; Wang, J.; Su, H. Transport properties of $\mathrm{HfO}_{2-\mathrm{x}}$ based resistive-switching memories. Phys. Rev. B 2012, 85, 195322. [CrossRef]

45. Chiu, F. A review on conduction mechanisms in dielectric films. Adv. Mater. Sci. Eng. 2014, 2014, 578168. [CrossRef]

46. Shaposhnikov, A.V.; Perevalov, T.V.; Gritsenko, V.A.; Cheng, C.H.; Chin, A. Mechanism of $\mathrm{GeO}_{2}$ resistive switching based on the multi-phonon assisted tunneling between traps. Appl. Phys. Lett. 2012, 100, 243506. [CrossRef]

47. Yen, T.J.; Chin, A.; Gritsenko, V. High performance all nonmetal $\mathrm{SiN}_{\mathrm{x}}$ resistive random access memory with strong process dependence. Sci. Rep. 2020, 10, 2807. [CrossRef]

48. Chang, M.F.; Lee, P.T.; McAlister, S.P.; Chin, A. Low sub-threshold swing HfLaO/Pentacene oganic thin film transistors. IEEE Electron. Device Lett. 2008, 29, 215-217. [CrossRef]

49. Lee, H.J.; Abe, K.; Noh, H.Y.; Kim, J.S.; Lee, H.; Lee, M.L. Analysis of the hump phenomenon and needle defect states formed by driving stress in the oxide semiconductor. Sci. Rep. 2019, 9, 11977. [CrossRef] [PubMed]

50. Yu, D.S.; Wu, C.H.; Huang, H.C.; Chin, A.; Chen, W.J.; Zhu, C.X.; Li, M.F.; Kwong, D.L. Fully silicided NiSi and germanided NiGe dual gates on $\mathrm{SiO}_{2} \mathrm{n}$ - and p-MOSFETs. IEEE Electron. Device Lett. 2003, 24, 739-741. [CrossRef]

51. Wu, C.H.; Hung, B.F.; Chin, A.; Wang, S.J.; Wang, X.P.; Li, M.F.; Zhu, C.; Yen, F.Y.; Hou, Y.T.; Jin, Y.; et al. High-temperature stable HfLaON p-MOSFETs with high-work-function $\operatorname{Ir}_{3}$ Si gate. IEEE Electron. Device Lett. 2007, 28, 292-294. [CrossRef]

52. Lin, S.H.; Cheng, C.H.; Chen, W.B.; Yeh, F.S.; Chin, A. Low-threshold-voltage TaN/Ir/LaTiO p-MOSFETs incorporating lowtemperature-formed shallow junctions. IEEE Electron. Device Lett. 2009, 30, 681-683. [CrossRef]

53. Chang, M.F.; Lee, P.T.; Chin, A. Low-threshold-voltage MoN/HfAlO/SiON p-MOSFETs with 0.85-nm EOT. IEEE Electron. Device Lett. 2009, 30, 861-863. [CrossRef]

54. $\mathrm{Wu}$, Y.H.; Chin, A. High temperature formed SiGe p-MOSFETs with good device characteristics. IEEE Electron. Device Lett. 2000, 21, 350-352. [CrossRef] 
55. Huang, C.H.; Chen, S.B.; Chin, A. $\mathrm{La}_{2} \mathrm{O}_{3} / \mathrm{Si}_{0.3} \mathrm{Ge}_{0.7}$ p-MOSFETs with high hole mobility and good device characteristics. IEEE Electron. Device Lett. 2002, 23, 710-712. [CrossRef]

56. Yu, D.S.; Huang, C.H.; Chin, A.; Zhu, C.; Li, M.F.; Cho, B.J.; Kwong, D.L. $\mathrm{Al}_{2} \mathrm{O}_{3}$ /Ge-On-Insulator n- and p-MOSFETs with Fully NiSi and NiGe Dual Gates. IEEE Electron. Device Lett. 2004, 25, 138-140. [CrossRef]

57. Takagi, S.; Toriumi, A.; Iwase, M.; Tango, H. On the universality of inversion layer mobility in Si MOSFET's: Part I-effects of substrate impurity concentration. IEEE Trans. Electron. Device 1994, 41, 2357-2362. [CrossRef]

58. Lin, C.Y.; Yu, D.S.; Chin, A.; Zhu, C.; Li, M.F.; Kwong, D.L. Fully silicided NiSi gate on $\mathrm{La}_{2} \mathrm{O}_{3}$ MOSFETs. IEEE Electron. Device Lett. 2003, 24, 348-350. [CrossRef]

59. Wu, Y.H.; Yang, M.Y.; Chin, A.; Chen, W.J. Electrical characteristics of high quality $\mathrm{La}_{2} \mathrm{O}_{3}$ dielectric with equivalent oxide thickness of $5 \AA$ A. IEEE Electron. Device Lett. 2000, 21, 341-343. [CrossRef]

60. Tsai, C.Y.; Chiang, K.C.; Lin, S.H.; Hsu, K.C.; Chi, C.C.; Chin, A. Improved capacitance density and reliability of High-k $\mathrm{Ni} / \mathrm{ZrO}_{2} / \mathrm{TiN}$ MIM capacitors using laser annealing technique. IEEE Electron. Device Lett. 2010, 31, 749-752. [CrossRef]

61. Chin, A.; Lin, B.C.; Chen, W.J.; Lin, Y.B.; Tsai, C. The effect of native oxide on thin gate oxide integrity. IEEE Electron. Device Lett. 1998, 19, 426-428. [CrossRef]

62. Chiang, K.C.; Chin, A.; Lai, C.H.; Chen, W.J.; Cheng, C.F.; Hung, B.F.; Liao, C.C. Very high $\mathrm{k}$ and high density TiTaO MIM capacitors for analog and RF applications. In Proceedings of the Digest of Technical Papers 2005 Symposium on VLSI Technology, Kyoto, Japan, 14-16 June 2005; pp. 62-63.

63. Lin, S.H.; Chiang, K.C.; Chin, A.; Yeh, F.S. High density and low leakage current $\mathrm{MIM}_{\text {capacitor using stacked } \mathrm{TiO}} / \mathrm{ZrO}_{2}$ insulators. IEEE Electron. Device Lett. 2009, 30, 715-717. [CrossRef] 